\title{
Regulation of B-Cell-Activating Factor Expression on the Basophil Membrane of Allergic Patients
}

\author{
Monica Boita ${ }^{a}$ Enrico Heffler ${ }^{a}$ Stefano Pizzimentia Alberto Raie $^{a}$ Elona Saraci ${ }^{b}$ \\ Paola Omedè ${ }^{b}$ Claudia Bussolino ${ }^{a}$ Caterina Bucca ${ }^{a}$ Giovanni Rolla ${ }^{a}$ \\ aDivision of Allergy and Immunology, Department of Medical Science, Azienda Ospedaliera Ordine Mauriziano Umberto I, \\ and ${ }^{b}$ Division of Hematology, Azienda Ospedaliera Città della Salute e della Scienza di Torino, University of Turin, Turin, Italy
}

\section{Key Words}

Allergic bronchopulmonary aspergillosis · Aspergillus fumigatus $\cdot$ B-cell-activating factor $\cdot$ Basophil $\cdot$ Basophil activation test · Fungal sensitization · lgE · Severe asthma . TLR-2

\begin{abstract}
Background: To investigate the modulation of B-cell-activating factor (BAFF) expression on the basophil membrane of allergic patients. BAFF is an important regulator of B-cell activation, proliferation and immunoglobulin production, which may play a role in respiratory allergic diseases in promoting the production of IgE by B cells. Methods: Peripheral blood samples of 10 patients with allergic rhinitis, 3 with severe asthma and fungal sensitization (SAFS), 3 with allergic bronchopulmonary aspergillosis (ABPA) and 11 healthy controls were assessed regarding BAFF (CD257) expression using the basophil activation test before and after stimulation with IgE and allergens, as well lgE-independent stimuli, like fMLP, lipotheichoic acid from Staphylococcus aureus (LTA-SA) and lipopolysaccharide (LPS). Results: BAFF membrane expression did not change after lgE and allergen stimulation both in patients and controls, while it was upregulated by Aspergillus stimulation, both in sensitized patients and controls. In both patients and controls, BAFF expression was sig-
\end{abstract}

nificantly upregulated following LTA-SA and $\beta-1,3$-glucan exposure (toll-like receptor-2 ligands), but not following LPS stimulation. Conclusions: Basophils from allergic and healthy subjects constitutively express membrane BAFF, which is not upregulated by lgE or specific allergens but by TLR-2 ligands (LTA-SA and $\beta$-1,3-glucan). Aspergillus fumigatus stimulation was able to upregulate BAFF expression on the basophils of sensitized asthmatic patients, but not via IgE-dependent mechanisms, since results did not differ between the patient and control groups. These findings suggest that basophils may contribute to the polyclonal production of IgE commonly observed in patients with SAFS and ABPA.

(c) 2015 S. Karger AG, Basel

\section{Introduction}

B-cell-activating factor (BAFF) is an important regulator of B-cell activation, proliferation and immunoglobulin production. It plays an important role in autoimmune diseases [1]. Recent observations indicate that BAFF may also play a role in respiratory allergic diseases [2]. Allergic rhinitis and asthma are characterized by the production of IgE specific for ubiquitous allergens (e.g. pollen, mites and molds); in some patients, an increase in total unspecific IgE may be observed, particularly in patients with

\section{KARGER 125}

(c) 2015 S. Karger AG, Base

$1018-2438 / 15 / 1663-0208 \$ 39.50 / 0$ 
severe asthma combined with fungal sensitization (SAFS) [3] or with allergic bronchopulmonary aspergillosis (ABPA) [4]. B-cell-stimulating factors such as BAFF are thought to play a role in promoting the production of $\operatorname{IgE}$ by $B$ cells. It has been shown that allergen-specific B cells are activated and undergo class switch recombination at allergic reaction sites $[5,6]$, and the release of BAFF in bronchoalveolar lavage fluid has been reported after specific allergen challenge in allergic asthmatics [2]. Basophils are an important component of both immediate allergic reactions and chronic inflammation, and due to their myeloid origin, these cells may be a source of BAFF production. The mechanisms of BAFF expression or release by basophils are only partly known. Chen et al. [7] demonstrated that IgD-binding antigens increased basophil expression of BAFF, and activation of toll-like receptors (TLRs) in basophils from healthy controls induced IgG4 production by B cells, an effect associated with enhanced production of BAFF [8]. These observations also point to a role of basophils in adaptive immune responses, similar to other cells of the innate immune system, including neutrophils, macrophages and monocytes [9, 10]. The aim of this study was to investigate whether BAFF is expressed on the basophil membrane of allergic patients and whether its membrane expression is increased by IgE-dependent stimuli, such as allergen exposure, and/or IgE-independent stimuli, including TLR engagement. Specifically, we were interested to investigate the effect of Aspergillus stimulation on BAFF expression on the basophil membrane of patients with SAFS or ABPA, who showed high serum levels of total IgE.

\section{Patients and Methods}

\section{Study Design}

Peripheral blood samples of 16 allergic rhinitis patients (aged $48 \pm 17.1$ years: 10 males and 6 females) with or without asthma and 11 healthy controls (aged $51 \pm 12.5$ years; 7 males and 4 females) were assessed for BAFF (CD257) expression following the basophil activation test (BAT) before and after IgE stimulation with specific allergens (e.g. grass, ragweed and Aspergillus fumigatus) and the TLR-4 ligand, lipopolysaccharide (LPS). In the 6 Aspergillus-sensitized patients ( 3 had severe asthma, total IgE: $418 \pm 348 \mathrm{kU} / \mathrm{l} ; 3$ had ABPA, total IgE: 2,399 \pm 1,265 kU/l), BAT was also performed after stimulation with the TLR-2 ligands, lipotheichoic acid from Staphylococcus aureus (LTA-SA) and $\beta-1,3-$ glucan from Euglena gracilis, as well as fMLP, as IgE-independent stimuli. BAFF mRNA expression was quantified by RT-PCR in 2 patients and 2 controls. All the patients and controls gave their informed consent to participate in the study, which was approved by the local institutional review board. The patients' demographic and clinical characteristics are reported in table 1.
Table 1. Clinical and demographic characteristics of the allergic patients $(n=16)$ grouped according to allergen sensitization

\begin{tabular}{lcccl}
\hline & Ragweed & Grass & A. fumigatus & $\begin{array}{l}\text { Total IgE, } \\
\mathrm{kU} / \mathrm{l} \\
(\mathrm{mean} \pm \mathrm{SD})\end{array}$ \\
& & & & \\
\hline $\begin{array}{l}\text { Gender } \\
\quad \text { Male }\end{array}$ & 2 & 4 & 4 & - \\
$\quad$ Female & 3 & 1 & 2 & - \\
$\begin{array}{l}\text { Age } \\
\quad \text { (mean } \pm \text { SD) }\end{array}$ & $39.5 \pm 13.5$ & $57 \pm 12.5$ & $60 \pm 15.5$ & - \\
$\begin{array}{l}\text { Rhinitis } \\
\text { Rhinitis + asthma }\end{array}$ & 3 & 2 & - & - \\
Severe asthma & - & 3 & - & - \\
ABPA & - & - & 3 & $418 \pm 347.8$ \\
\hline
\end{tabular}

\section{Basophil Activation Test}

BAT was performed according to a previously reported technique. Briefly, endotoxin-free heparinized whole-blood samples were obtained from allergic patients and healthy controls. Cells were challenged with $100 \mu \mathrm{l}$ of anti-IgE $(10 \mu \mathrm{g} / \mathrm{ml}$; clone G7-18; BD Bioscience, USA), allergens $(0.2 \mu \mathrm{g} / \mathrm{ml}$ ragweed, $2.5 \mu \mathrm{g} / \mathrm{ml}$ grass and $2.5 \mu \mathrm{g} / \mathrm{ml}$ A. fumigatus; ALK Abelló, Italy), fMLP $(0.5 \mu \mathrm{g} / \mathrm{ml}$; Sigma Aldrich, Italy) or TLR ligands $(1 \mu \mathrm{g} / \mathrm{ml}$ LTASA and $2.5 \mu \mathrm{g} / \mathrm{ml} \beta$-1,3-glucan; both from InvivoGen, USA, and $1 \mu \mathrm{g} / \mathrm{ml}$ LPS from Escherichia coli; Sigma Aldrich) for $20 \mathrm{~min}$ at $37^{\circ} \mathrm{C}$ in a water bath (optimal stimulation times were assessed in previous experiments). The optimal stimulation concentrations of the anti-IgE, allergens, fMLP and TLR ligands were established in preliminary experiments. As a negative control, Tyrode solution (Sigma Aldrich) with $20 \mu \mathrm{M}$ HEPES and 7.5\% $\mathrm{NaHCO}_{3}, \mathrm{pH}$ 7.4, was used to assess the spontaneous expression of the different markers. The reactions were terminated by chilling the cells on ice.

Immunophenotyping and Flow-Cytometric Analyses

Basophils were stained with $5 \mu$ l of anti-human FceRIa-Pacific Blue (BioLegend, USA), $10 \mu$ of anti-human CD63-FITC (clone H5C6; BD Biosciences), $10 \mu \mathrm{l}$ of anti-human CD203c-APC (clone NP4D6; BioLegend) and $10 \mu \mathrm{l}$ of monoclonal anti-human CD257PE (BioLegend) for $20 \mathrm{~min}$ on ice. Flow-cytometric analyses were performed on a FACSCanto II flow cytometer (BD Immunocytometry Systems, USA). Side scatter and anti-IgE+/CD203c+ staining were applied to gate out at least 500 basophils. BAFF positivity was set on basophils with a fluorescence intensity that was above the level of the 99th percentile of a FMO (Fluorescence Minus One) sample.

\section{Basophil Purification}

Basophils were isolated using immunomagnetic methods (MACS basophil isolation kit II; Miltenyi). Briefly, PBMCs from 2 healthy subjects and 2 allergic patients were resuspended in PBS with $0.5 \%$ BSA and 2 mM EDTA, and were incubated with a basophil biotin antibody cocktail after FcR blocking. The basophils that were assessed by flow cytometry (using FceRIa-Pacific Blue and CD203c-APC) accounted for more than $95 \%$ of the total cells. 


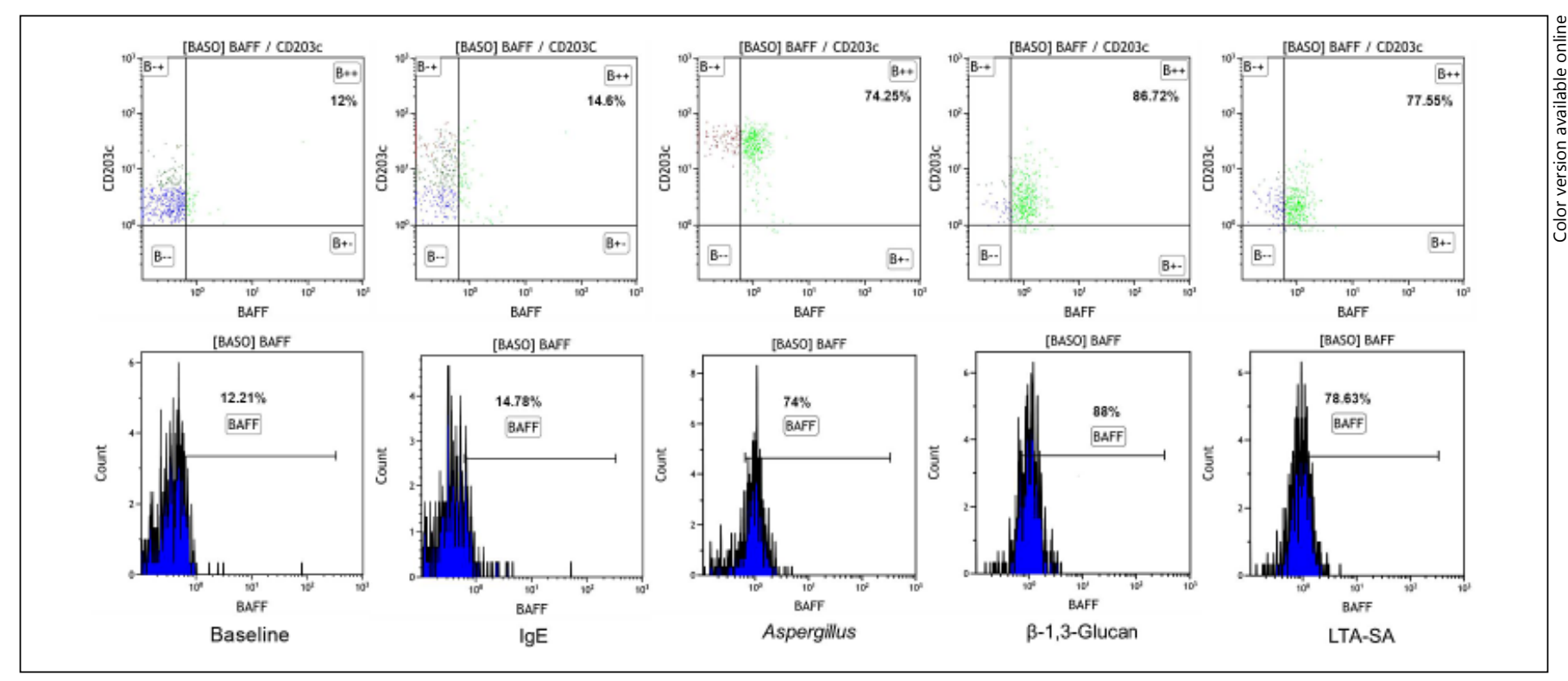

Fig. 1. The effect of basophil stimulation on membrane BAFF expression in a patient. Basophils were gated as IgE+/CD203c+. A. $f u$ migatus, LTA-SA and $\beta$-1,3-glucan induce significant upregulation of BAFF on the basophil membrane.

Real-Time PCR Analysis for BAFF mRNA Expression

Total RNA from purified basophils was extracted after lysis in TRIzol reagent (Invitrogen Life Technologies). RNA samples were reverse transcribed at $42^{\circ} \mathrm{C}$ with a reverse transcription system (Promega, USA) according to the manufacturer's instructions, and the subsequent cDNA was used for real-time PCR. Quantitative real-time PCR assays were performed using primers that specifically amplified BAFF and G6PD (Hs00198106_m1 and Hs00166169_m1, respectively; purchased from Applied Biosystems). RT-PCR was performed with a BioRad iQ iCycler (BioRad, USA) and analyzed with the gene expression analysis for iCycler iQ real-time PCR detection system software (BioRad). BAFF and G6PD primer amplification efficiencies were validated in a preliminary experiment. For PCR analysis, each sample was run in duplicate in separate tubes. The results were normalized to a housekeeping gene (G6PD), as shown by Vandesompele et al. [11].

\section{Statistics}

All the variables are reported as means $\pm \mathrm{SD}$. Comparisons between patients and controls were performed using Student's t test for paired data. All statistical analyses were performed using GraphPad, Prism 4.

\section{Results}

BAFF was constitutively expressed on the basophil membrane (fig. 1), with no difference between the allergic patients (19 $\pm 15.8 \%$ basophils) and controls (19.3 \pm $10.5 \%$ basophils).

\section{BAFF mRNA Expression}

BAFF mRNA expression on purified nonstimulated basophils did not differ between patients and controls, confirming the flow-cytometric finding (data not shown).

\section{IgE-Dependent Stimuli}

BAFF membrane expression did not change after IgE stimulation in both patients and controls (from $19 \pm 15.8$ to $25.3 \pm 17.4$ in patients, and from $19.3 \pm 10.5$ to $19.6 \pm 9.6$ in controls), whereas CD63 was upregulated as expected. BAFF membrane expression did not significantly change following grass and ragweed stimulation (from $13.8 \pm 17.8$ to $23.5 \pm 16.8$ in patients, and from $17.7 \pm 9.6$ to $23.6 \pm 9.4$ in controls), whereas CD63 expression was significantly upregulated (from $0.33 \pm 0.12$ to $33.4 \pm 0.28, \mathrm{p}<0.0001$ ) on the allergic patients' basophil membranes as expected.

\section{Aspergillus Stimulation}

BAFF expression was significantly upregulated on the basophil membrane of patients and controls following $A$. fumigatus stimulation (from $27.7 \pm 11.7$ to $57 \pm 17.1$ in patients, $\mathrm{p}=0.0012$, and from $27.8 \pm 6.2$ to $58.3 \pm 7.6, \mathrm{p}=$ 0.0002 , in controls; fig. $2 \mathrm{a}$ ).

\section{IgE-Independent Stimuli}

In both patients and controls, BAFF expression was significantly upregulated following LTA-SA (from $26.4 \pm$ 12.9 to $63 \pm 10.6$ in patients, $p=0.0063$, and from $20 \pm 8.7$ 


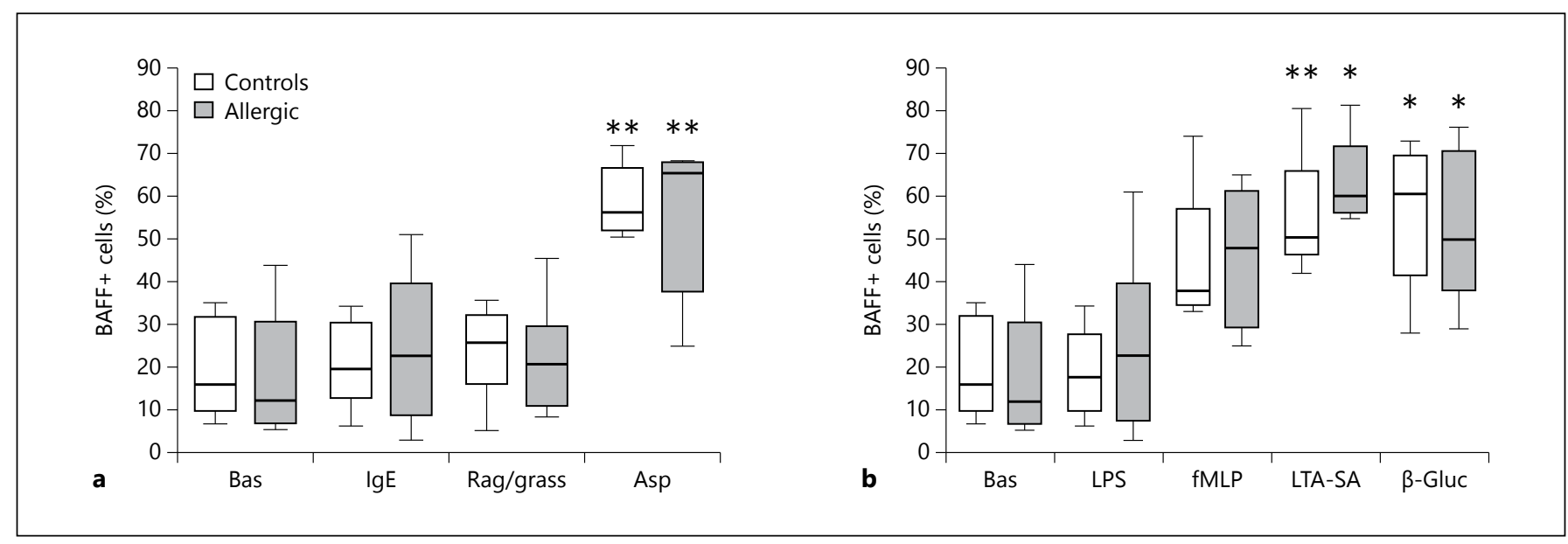

Fig. 2. The percentage of BAFF-positive cells at baseline, after IgE and allergen stimulation (a), and after non-IgE-related (b) stimuli in controls and allergic subjects. Rag $=$ Ragweed; grass $=$ grass pollen; Asp $=$ A. fumigatus. Bas $=$ baseline; $\beta$-Gluc $=\beta-1,3$-glucan. ${ }^{*} p<0.05$, ** $\mathrm{p}<0.01$.

to $55.2 \pm 16.8$ in controls, $\mathrm{p}=0.023)$ and $\beta$-1,3-glucan exposure (from $26.4 \pm 12.9$ to $53.4 \pm 18$ in patients, $\mathrm{p}=$ 0.036 , and from $20 \pm 8.7$ to $55.5 \pm 19.7$ in controls, $\mathrm{p}=$ 0.021). Following fMLP exposure, BAFF expression did not significantly increase in patients (from $26.4 \pm 12.9$ to $45.6 \pm 16.5, \mathrm{p}=0.15)$; however, it increased almost significantly in controls (from $20 \pm 8.7$ to $45.7 \pm 19, \mathrm{p}=0.06$ ). Additionally, LPS stimulation did not change BAFF expression in either patients or controls (fig. 2b).

\section{Discussion}

Our results show that basophils of allergic and healthy subjects constitutively expressed membrane BAFF and that its expression was not upregulated by IgE or specific allergens, though it was upregulated by TLR-2 ligands (LTA-SA and $\beta$-1,3-glucan). A. fumigatus stimulation was able to upregulate BAFF expression on the sensitized asthmatic patients' basophils, which showed also increased CD203c and CD63 expression, as expected. The mechanism of BAFF expression could not be explained by an IgE-dependent pathway, as the same level of BAFF upregulation was also observed in nonallergic controls, who did not show any changes in CD203c and CD63 expression. Considering the fast stimulation time (20 $\mathrm{min})$, it is conceivable that BAFF is contained in a vesicle storage compartment and that TLR-2 stimulation promotes the specific granules to be fused to the plasma membrane and expressed. Similarly to the independent CD203c and CD63 membrane expression, which is regulated by the activation/degranulation of cells [12], our results suggest that BAFF expression might follow a specific pathway of activation that is independent of degranulation/CD63 expression and CD203c/CD11b expression.

TLRs recognize fungal pathogen motifs, including Aspergillus motifs, and both TLR-2 and TLR- 4 have been shown to recognize A. fumigatus hyphae [13]. In our experiments, LPS, a TLR-4 ligand, was not able to upregulate membrane BAFF, indicating that membrane BAFF expression may be upregulated by A. fumigatus following TLR-2 engagement. Watanabe et al. [8] demonstrated that LPS induced the release of BAFF, suggesting a possible difference between surface expression and the release of BAFF after TLR-4 stimulation.

Following fMLP exposure, another IgE-independent stimulus, BAFF expression increased, even if the increase was not significant, due to the broad distribution of the response, suggesting that there is heterogeneity in the studied population, where certain individuals have a propensity to express more BAFF following stimulation with fMLP. The reasons for this heterogeneous response are not clear.

We did not measure BAFF release from basophils because our observation was limited to its membrane expression, but BAFF membrane expression may be an important step toward its release. Membrane BAFF cleavage by inflammatory cytokines has been reported to be a mechanism of BAFF release by neutrophils [14].

Basophils are cells of myeloid origin, similar to neutrophils, and migrate from the blood compartment to inflamed tissue, where they act as both effector inflamma- 
tory cells and cells that are involved in pathways linking innate to adaptive immunity. Specifically, basophils may help to regulate the adaptive immune response because they are a known early source of IL- 4 and other cytokines associated with Th2 responses [15]. Our finding that BAFF is constitutively expressed on the basophil membrane of allergic patients may have implications for the activation of immunoglobulin production and class switching recombination. Other cells, such as epithelial cells, may produce BAFF and participate in the promotion of local IgE production, as reported for chronic rhinosinusitis with nasal polyps [16], where sinonasal tissue BAFF mRNA expression was significantly correlated with CD20 expression [17].

The upregulation of BAFF expression on the basophil membrane that we observed following Aspergillus stimulation may be related to the huge amount of polyclonal $\operatorname{IgE}$ production that is commonly observed in patients with SAFS and to an even higher degree in ABPA patients, the airways of whom are colonized by Aspergillus [3, 4].
In conclusion, our results demonstrate that basophils constitutively express BAFF on their membranes, both in allergic and in healthy subjects, and are able to upregulate its expression through non-IgE-mediated stimulation. These findings suggest that basophils, like other cells of innate immunity, help to establish a link between innate and adaptive immune responses, specifically following TLR stimulation.

\section{Acknowledgment}

This study was supported by ASIMAS (Italian Association of Patients with Mastocytosis) and the 'Fondazione Scientifica Mauriziana' (a non-governmental, non-profit scientific foundation).

\section{Disclosure Statement}

The authors have no conflict of interest to declare.

\section{References}

1 Schneider P, MacKay F, Steiner V, Hofmann $\mathrm{K}$, Bodmer JL, Holler N, et al: BAFF, a novel ligand of the tumor necrosis factor family, stimulates B cell growth. J Exp Med 1999;189: 1747-1756.

-2 Kato A, Qing Xiao H, Chustz RT, Liu MC, Schleimer RP: Local release of B cell-activating factor of the TNF family after segmental allergen challenge of allergic subjects. J Allergy Clin Immunol 2009;123:369-375.

-3 Denning DW, O’Driscoll BR, Hogaboam CM, Bowyer P, Niven RM: The link between fungi and severe asthma: a summary of the evidence. Eur Respir J 2006;27:615-626.

-4 Agarwal R, Chakrabarti A, Shah A, Gupta D, Meis JF, Guleria R, Moss R, Denning DW; ABPA complicating asthma ISHAM working group: Allergic bronchopulmonary aspergillosis: review of literature and proposal of new diagnostic and classification criteria. Clin Exp Allergy 2013;43:850873.

5 Fiset PO, Cameron L, Hamid Q: Local isotype switching to IgE in airway mucosa. J Allergy Clin Immunol 2005;116:233-236.

6 Gould HJ, Takhar P, Harries HE, Durham SR Corrigan CJ: Germinal-centre reactions in allergic inflammation. Trends Immunol 2006; 27:446-452.
7 Chen K, Xu W, Wilson M, He B, Miller NW, Bengten E, Edholm E, Santini PA, Rath P, Chiu A, Cattalini M, Litzman J, Bussel J, Huang B, Meini A, Riesbeck K, CunninghamRundles C, Plebani A, Cerutti A: Immunoglobulin $\mathrm{D}$ enhances immune surveillance by activating antimicrobial, proinflammatory and B cell-stimulating programs in basophils. Nat Immunol 2009;10:889-898.

8 Watanabe T, Yamashita K, Sakurai T, Kudo M, Shiokawa M, Uza N, Kodama Y, Uchida K, Okazaki K, Chiba T: Toll-like receptor activation in basophils contributes to the development of IgG4-related disease. J Gastroenterol 2013;48:247-253.

9 Mackay F, Schneider P: Cracking the BAFFcode. Nat Rev Immunol 2009;9:491-502.

10 Nardelli B, Belvedere O, Roschke V, Moore PA, Olsen HS, Migone TS, Sosnovtseva S, Carrell JA, Feng P, Giri JG, Hilbert DM: Synthesis and release of B-lymphocyte stimulator from myeloid cells. Blood 2001;97:198-204.

11 Vandesompele J, De Preter K, Pattyn F, et al: Accurate normalization of real-time quantitative RT-PCR data by geometric averaging of multiple internal control genes. Genome Biol 2002; 3:RESEARCH0034.

12 MacGlashan D Jr: Marked differences in the signaling requirements for expression of
CD203c and CD11b versus CD63 expression and histamine release in human basophils. Int Arch Allergy Immunol 2012;159:243-252.

13 Mambula SS, Sau K, Henneke P, Golenbock DT, Levitz SM: Toll-like receptor (TLR) signaling in response to Aspergillus fumigatus. J Biol Chem 2002;277:39320-39326.

-14 Assi LK, Wong SH, Ludwig A, Raza K, Gordon C, Salmon M, et al: Tumor necrosis factor alpha activates release of $B$ lymphocyte stimulator by neutrophils infiltrating the rheumatoid joint. Arthritis Rheum 2007;56:17761786.

15 Chirumbolo S: State-of-the-art review about basophil research in immunology and allergy: is the time right to treat these cells with the respect they deserve? Blood Transfus 2012;10: 148-164.

16 Small P, Barrett D, Frenkiel S, Rochon L, Cohen C, Black M: Local specific IgE production in nasal polyps associated with negative skin tests and serum RAST. Ann Allergy 1985;55: 736-739.

-17 Kato A, Peters A, Suh L, Carter R, Harris KE, Chandra R, et al: Evidence of a role for B cellactivating factor of the TNF family in the pathogenesis of chronic rhinosinusitis with nasal polyps. J Allergy Clin Immunol 2008; 121:1385-1392. 